\title{
PERANAN BUPATI CILACAP PERTAMA RADEN TUMENGGUNG TJAKRAWERDANA II DALAM PEMBANGUNAN KOTA CILACAP 1856-1873
}

\author{
Toni', Yat Rospia Brata $^{2}$, Yeni Wijayanti ${ }^{3}$ \\ 1,2,3 Program Studi Pendidikan Sejarah, Universitas Galuh, Jl. R.E. Martadinata No, 150, Ciamis, Indonesia \\ Email: tonibaktimanggala@gmail.com¹, yatrospia@gmail.com², yeniunigal@gmail.com³
}

\begin{abstract}
Cilacap City is the administrative center of Cilacap Regency, which is experiencing very rapid development. The first figure, Raden Tumenggung Tjakrawerdana II, cannot be separated from the first person to build this city. His role in building Cilacap City is an exciting thing to study. This study was to determine the biography of the first Regent of Cilacap and his role in making the city of Cilacap. The method used is the historical method, namely 1) topic selection, 2) heuristics, 3) source criticism, 4) interpretation, 5) historiography. The result from this research is; 1) The First Regent of Cilacap is the 12th son of the Regent of Banyumas. He is married to 6 women and has 18 sons and daughters; he died, and the Karang Suci cemetery is a place where he buried, 2) his role in building Cilacap City included; built Rawa Si Glongong, building the Regency Hall, building the Grand Mosque, building the Protocol Road, Assistant-Resident Building, building the Cilacap Port, and building the Kali Yoso Canal. Several heritage buildings have until now functioned as the Cilacap Regency Government and other public facilities.
\end{abstract}

Keywords: Regent of Cilacap, City of Cilacap, Raden Tumenggung Tjakrawerdana II.

\begin{abstract}
ABSTRAK
Kota Cilacap merupakan pusat pemerintahan Kabupaten Cilacap yang mengalami perkembangan yang sangat pesat. Sosok pertama, Raden Tumenggung Tjakrawerdana II, tak lepas dari orang pertama yang membangun kota ini. Perannya dalam membangun Kota Cilacap merupakan hal yang menarik untuk dikaji. Penelitian ini untuk mengetahui biografi Bupati Cilacap pertama dan perannya dalam membangun kota Cilacap. Metode yang digunakan adalah metode sejarah, yaitu 1) pemilihan topik, 2) heuristik, 3) kritik sumber, 4) interpretasi, 5) historiografi. Hasil dari penelitian ini adalah; 1) Bupati Pertama Cilacap adalah putra ke-12 Bupati Banyumas. la menikah dengan 6 wanita dan memiliki 18 putra dan putri; beliau meninggal, dan makam Karang Suci adalah tempat beliau dimakamkan, 2) perannya dalam membangun Kota Cilacap antara lain; membangun Rawa Si Glongong, membangun Balai Kabupaten, membangun Masjid Raya, membangun Jalan Protokol, Gedung Assisten Residen, membangun Pelabuhan Cilacap, dan membangun Kanal Kali Yoso. Beberapa bangunan cagar budaya hingga saat ini masih difungsikan sebagai Pemkab Cilacap dan fasilitas umum lainnya.
\end{abstract}

Kata kunci: Bupati Cilacap, Kota Cilacap, Raden Tumenggung Tjakrawerdana II.

Cara sitasi: Toni., Brata, Y. R., \& Wijayanti, Y. (2021). Peranan Bupati Cilacap Pertama Raden Tumenggung Tjakrawerdana II Dalam Pembangunan Kota Cilacap 1856-1873. J-KIP (Jurnal Keguruan dan IImu Pendidikan), 2 (3), 11-20. 


\section{PENDAHULUAN}

Kabupaten Cilacap merupakan salah satu Kabupaten yang ada di Provinsi Jawa Tengah bagian Barat dan berbatasan langsung dengan Provinsi Jawa Barat, Kabupaten Cilacap di masa lalu menjadi bagian dari beberapa penguasa mulai dari zaman kuno Hindu Budha, masa Islam, masa kolonialisme dan sampai dengan sekarang. Secara historis daerah yang menjadi cikal bakal Kabupaten Cilacap dapat dilacak dari berbagai sumber diantaranya dari masa Hindu Budha terdapat dalam Prasasti Salingsingan 802 saka, Prasasti Er Hangat 885 M, Prasasti Panunggalan 896 M, Prasasti Pabuharan 900 M, Prasasti Luitan 901 M. Selain dari prasasti sumber lain yang memuat tentang Cilacap diantaranya Naskah Bujangga Manik, Serat Babad Tanah Jawi, Babad Pasir Luhur, dan Naskah Lontar Ayam Alas (Dwiyanto, 2003).

Pada masa Kerajaan Mataram Islam, wilayah Cilacap masuk kedalam daerah Mancanegara Kilen dengan pusat pemerintahan di Banyumas, setelah disepakatinya hasil Perjanjian Giyanti Kerajaan Mataram Islam kemudian dipecah menjadi dua yaitu Kesunanan Surakarta dan Kesultanan Yogyakarta pada tanggal 13 Februari 1755 dan memasukan wilayah Cilacap yang pada saat itu masih menjadi satu dengan Banyumas ke dalam kekuasaan Kesunanan Surakarta (Astrid, 2018).

Wilayah Banyumas atau Mancanegara Kilen (Barat) mencakup beberapa daerah diantaranya Banyumas, Banjar, Pasir, Ayah, Roma, Karang Bolong, Merdan, Warah, Tresna, Karencang, Bobotsari, Kertanegara, Lebaksiu, Balapulung, Bentar dan Dayeuh Luhur. Kekacauan yang terjadi di Pulau Jawa yaitu meletusnya Perang Diponegoro membawa dampak yang sangat besar pada perubahan peta perpolitikan dan sosial khususnya di wilayah Kasunanan Surakarta yaitu adanya tuntutan Pemerintah Hindia Belanda kepada Sunan untuk membayar ganti rugi, Wilayah Banyumas menjadi bayaran untuk ganti rugi akibat Perang tersebut dan serah terima dilakukan di Surakarta tanggal 22 Februari 1830 (Wibowo, 2002).

Kebijakan tanam paksa mulai diterapkan di Wilayah Banyumas, motif tanam paksa tahun 1830 adalah untuk mengatasi masalah finansial yang dihadapi Hidia Belanda karena Perang Diponegoro tahun 1825-1830, sehingga Gubernur Jenderal Van den Bosch mengusulkan menerapkan sistem tanam paksa sebagai upaya mengisi kas negara yang kosong atau menutup defisit anggaran pemerintah Belanda (Sondarika, tt:59)

Wilayah Banyumas yang luas dirasa kurang efektif jika dikelola oleh Bupati Banyumas dan Bupati Purwekerto, untuk memudahkan pengelolaan daerah ini pemerintah Hindia Belanda mengeluarkan Besluit tertanggal 27 Juli 1841 yang isinya yaitu Kepatihan Dayeuh Luhur, Distrik Cilacap dan Distrik Adireja dipisahkan dari kabupaten Banyumas dan Purwokerto, distrik ini kemudian disatukan menjadi satu Afdeling tersendiri yaitu Afdeling Cilacap dengan ibukotanya Cilacap. Adapun yang menjadi pemimpin Afdeling ini yaitu seorang pribumi yang bergelar Ronggo yaitu Raden Bei Tjakradimeja didampingi seorang Asisten-Residen (Astrid, 2018).

Pada 1856 penduduk Banyumas khususnya Cilacap mengusulkan untuk meningkatkan posisi Cilacap yang awalnya Afdeling menjadi Onder-Regentschap (daerah setingkat kecamatan) dan kemudian ditingkatkan kembali menjadi Regentschap (daerah setingkat kabupaten) dengan persetujuan Gubernur Jenderal Mr. Albertus Jacob Duymaer van Twist melalui Bes/uit tertanggal 21 Maret 1856. Setelah status Cilacap ditingkatkan posisi Raden Bei Tjakradimeja yang semula hanya berkedudukan sebagai patih diangkat menjadi Bupati Cilacap melalui Bes/uit Gubernur Jenderal No. 17 tertanggal 6 Juli 1856 dengan gelar Raden Tumenggung Tjakrawerdana II (nunggak semi asma) menggunakan nama ayahnya sebagai nama gelar bupati (Soedarto, 1975).

Daerah Cilacap pada masa Bupati Raden Tumenggung Tjakrawerdana II mengalami perubahan signifikan baik dari segi sosial-ekonomi, budaya, infrastruktur dan lain-lain. Sehingga perhatian Belanda terhadap daerah ini sangat intens terutama setelah praktek tanam paksa 
dijalankan di Keresidenan Banyumas. Daerah Cilacap menjadi salah satu tempat terpenting untuk kegiatan ekspor dan impor hasil perkebunan dari Banyumas melalui pelabuhan Cilacap.

Adapun rumusan masalah penelitian ini yaitu Bagaimana biografi Bupati Cilacap Pertama Raden Tumenggung Tjakrawerdana II, dan peranannya dalam pembangunan Kota Cilacap 18561873. Tujuan dari penelitian ini adalah untuk mengetahui bagaimana biografi Bupati Cilacap Pertama Raden Tumenggung Tjakrawerdana II dan peranannya dalam pembangunan Kota Cilacap.

\section{METODE PENELITIAN}

Sebuah penelitian merupakan usaha menjawab permasalahan penelitian, maka diharuskan melalui serangkaian kegiatan yang dilaksanakan dengan menggunakan berbagai tahap secara rinci. Dalam penelitian ini, peneliti menggunakan metode historis, yaitu suatu proses pengkajian, penjelasan dan penganalisisan secara kritis terhadap rekaman atau penelitian masa lalu. Penelitian sejarah memiliki lima tahap yaitu pemilihan topik, heuristik (pengumpulan data), kritik sumber (Verifikasi), interpretasi (penafsiran), dan historiografi (penulisan sejarah) (Kuntowijoyo, 2013:69).

Sumber yang digunakan dalam penelitian ini, berdasarkan cara memperolehnya, dibagi menjadi dua yaitu: (a) Sumber Primer; merupakan kesaksian seorang saksi yang melihat dengan mata kepala sendiri atau melihat dengan pancaindra yang lain, atau dengan alat baik perekam, foto atau lukisan yang hadir pada saat peristiwa yang diceritakan terjadi (dan selanjutnya secara singkat disebut saksi pandangan mata) (Gottschalk, 2008:43). Adapun sumber primer yang peneliti gunakan diantaranya: Amuttetz J.E.Z. Kort Verlag de river in de residentie Banjoemas en terrein Tlatjap 1831, Pekalongan de 15 April 1831. Arsip Banyumas 20.5, Allgemeen Overzicht van deStaatkudige Geattelheid van Nederlandsche Indie Over 1830-1848, Besluit 30 Juli 1847 No 3, Besluit 6 Juli 1856 No. 17, Bundel Besluiten 20 Juli 1842 No 7, Staatsblad Nederlandsche Indie No 56. Jaar 1847; dan (b) Sumber Sekunder; yaitu sumber yang disampaikan bukan oleh saksi mata (Kuntowijoyo, 2013:75), adapun sumber sekunder yang digunakan antara lain: buku, jurnal, skripsi, artikel ataupun karya lain yang berkaitan dengan topik penelitian.

Kritik Sumber (Verifikasi) dilakukan untuk menentukan keabsahan data dengan cara penyaringan secara kritis terhadap sumber yang didapat, adapun cara dalam verifikasi sumber ini melalui kritik ekstern dan intern. Kritik ekstern digunakan untuk menilai keabsahan sumber dengan cara dilihat dari jenis tinta, kertasnya, gaya tulisan, bahasa, kalimat, huruf, dan semua penampilan luarnya guna mengetahui autentisitas atau keaslian sumber (Kuntowijoyo, 2013:77). Sedangkan kritik intern digunakan untuk menguji lebih jauh lagi mengenai isi dokumen, mempertanyakan apakah isi dokumen yang diperoleh itu benar dan dapat dipercaya, kredibel dan reliabel. Karena sumber sejarah juga dibuat oleh manusia maka harus dilakukan kritik ini untuk mengidentifikasi pengarang dan isi dokumen (Daliman, 2018:64).

Peneliti melakukan kritik intern dan ekstern terhadap sumber yang didapat, kritik intern dilakukan terhadap sumber primer diantaranya Besluit Gubernur Jenderal 6 Juli 1856, Besluit 30 Juli 1846, bundel bes/uiten No 122 Juli 1842 dan sumber primer lainnya diperiksa dengan seksama mulai dari isi sumber, kertas yang digunakan, tahun pembuatan yang tercantum dan gaya penulisan yang digunakan. Dari sumber yang ditemukan peneliti mengambil kesimpulan bahwa sumber ini dibuat sezaman dengan peristiwa yang sedang diteliti. Dan kritik ekstern dilakukan dengan cara membandingkan isi sumber primer dengan literatur lain atau hasil analisis dari penelitian sebelumnya, selain itu juga isi sumber dibandingkan dengan keterangan dari hasil wawancara dengan narasumber dan setelah melalui serangkaian pengujian maka diambil kesimpulan bahwa sumber yang didapat merupakan asli sumber primer.

Tahap Interpretasi (Penafsiran) merupakan proses penafsiran isi data-data yang didapat, hal ini sering disebut bidang subjektivitas sejarawan tanpa penafsiran sejarawan, data tidak dapat 
berbicara (Kuntowijoyo, 2013:78). Setelah peneliti melakukan kritik interen dan eksteren kemudian didapat sumber yang relevan selanjutnya sumber diinterpretasi atau ditafsirkan dari sumber primer dan sekunder peneliti menafsirkan sumber agar mudah dipahami dan memilah-milah sumber untuk kemudian disusun, hal ini dilakukan peneliti agar lebih mudah dalam proses penulisan.

Tahap akhir dari penelitian sejarah adalah Historiografi (Penulisan Sejarah), yang merupakan hasil dari rangkuman sumber-sumber yang sudah terverifikasi dan dituliskan dengan gaya bahasa yang baik dan benar sehingga menarik minat pembaca. Terlepas dari itu semua historiografi secara umum merupakan tahap akhir dari penelitian sejarah yaitu pencatatan secara kronologis dari bukti-bukti yang sudah dikumpulkan, dikritik, dan diinterpretasi menjadi satu karya tulis ilmiah.

\section{HASIL DAN PEMBAHASAN \\ Biografi Bupati Cilacap Pertama Raden Tumenggung Tjakrawerdana II}

Raden Tumenggung Tjakrawerdana II atau yang memiliki nama kecil Raden Bei Tjakardimeja merupakan Putra Raden Tumenggung Tjakrawerdana I Bupati Kasepuhan Banyumas dan memiliki 21 saudara laki-laki dan perempuan. Dalam usia yang sangat muda, Raden Bei Tjakradimeja sudah diangkat menjadi Patih Banyumas, hal ini tidak terlepas dari kepribadian beliau yang cakap, ulet, rajin dan pintar. Selama di Banyumas posisi penting yang diembannya yaitu Patih Banyumas sebelum akhirnya diperintahkan membuka alas Donan sebagai pemukiman baru, beliau dipilih untuk Babad Alas karena pada saat itu yang dinilai layak dan cakap hanya Raden Bei Tjakradimeja adapun sebelumnya dalam ajuan Residen Banyumas ada dua nama yaitu Raden Bei Tjakradimeja dan Raden Wiradika Patih Dayeuhluhur tetapi mengundurkan diri dari pencalonan yang akan membuka hutan Donan tersebut (Wawancara Soedarmadji 28 Maret 2021).

Menurut cerita, daerah Donan atau daerah yang akan dibuka sebagai kota baru ini bukan hanya menjadi sarang para perompak, juga menjadi sarang para makhluk halus penunggu hutan dan rawa-rawa di Cilacap cerita ini berkembang di masyarakat dan menjadi sebuah mitos yang diyakini keberadaanya, saat itu yang dianggap mampu dan memiliki keberanian untuk membuka hutan Cilacap hanya Raden Bei Tjakradimeja, sehingga beliau ditunjuk untuk membuka hutan Cilacap menjadi kota baru (Wawancara Wirendra Tjakrawedaja 1 Maret 2021).

Raden Bei Tjakradimeja membuka Alas Donan dibantu oleh Raden Cakranegara, Raden Cakranegara sendiri merupakan kakak dari Raden Bei Tjakradimeja. Dimasa mendatang Raden Cakranegara diangkat menjadi Bupati Banyumas menggantikan Ayahnya, selain Raden Cakranegara tokoh lain yang membantu dalam babad alas Donan ini yaitu Kyai Singawedana. Peran dari Kyai Singawedana sangat penting karena beliau menjadi tangan kanan Raden Tumenggung Tjakrawerdana II selama pembangunan Kota Cilacap (Soedarto, 1975).

Wilayah bagian barat Mataram sudah terlebih dulu dijadikan sebagai kaupaten sejak masa kepemimpinan Sultan Agung, seperti Sumedang larang, Bandung, Parakan Muncang dan Sukapura. Yang kemudian bertambah lagi dengan dipecahnya wilayah Galuh menjadi 5 Kabupaten yaitu Imbanagara, Bojonglompang, Ciancang (Utama), Kawasen (Banjarsari), Banyumas. Banyumas merupakan daerah pecahan dari Kerajaan Galuh (Ratih, 2017).

Raden Tumenggung Tjakrawerdana semasa hidupnya memiliki enam istri yaitu 3 garwa padmi dan 3 garwa hampean adapun nama istri yang teridentifikasi yaitu Raden Mas Ajeng Teja, Raden Mas Ajeng Tisna, dan Mbok Ajeng Sri. Dari keenam istrinya beliau dikaruniai 18 putra dan puteri yang salah satu diantaranya kelak akan meneruskan posisinya sebagai Bupati Cilacap yaitu Raden Bei Tjakarabrata sebagai Bupati Ke-2, Raden Bei Tjakradidjaja sebagai Bupati ke-3 dan Raden Panji Gatot sebagai Bupati ke-4. Raden Tumenggung Tjakrawedana II meninggal saat menghadiri pesta tahun baru di Pendopo Banyumas 1 Januari 1873, beliau wafat dikarenakan 
penyakit stroke yang diidapnya. Beliau dikebumikan di kompleks pemakaman keluarga Karang Suci, yang kini menjadi kompleks pemakaman umum Kota Cilacap (wawancara Wirendra Tjakrawerdaja 1 Maret 2021).

Peranan Bupati Cilacap Pertama Raden Tumenggung Tjakrawerdana II dalam Pembangunan Kota Cilacap 1856-1873

\section{1) Pengeringan Rawa Si Glongong}

Rombongan Raden Bei Tjakradimeja (Raden Tumenggung Tjakrawerdana II) sampai di Tonjong Wetan daerah ini digunakan sebagai pemukiman sementara, menurut Wirendra Tjarasewadja mengatakan bahwa sebelum pendopo yang sekarang berdiri rombongan singgah di daerah yang disebut Tonjong Wetan dekat dengan daerah Handaunan/Daunan/Donan. Pembangunan kota baru ini menghadapi tantangan salah satu tantangan terbesarnya yaitu terdapat rawa-rawa luas yang dikenal dengan nama Rawa Si Glongong, bukan hanya bentang alam yang menjadi faktor penghambat dalam pembangunan Kota Cilacap daerah rawa juga menjadi sarang nyamuk malaria yang mengancam kesehatan penduduk.

Dibawah komando Kyai Singawedana, proyek pengeringan rawa dimulai dengan proses pengurukan atau menimbun rawa diperkirakan yang terlibat dalam proyek pengeringan ini sekitar 10.000 orang yang didatangkan dari Banyumas termasuk rombongan Raden Bei Tjakradimeja. Adapun tanah untuk mengurug atau menimbun rawa Si Glongong diambil dari desa KuripanKesugihan, dari hasil pengurugan ini dibangun banyak fasilitas umum yang sampai sekarang masih berdiri kokoh seperti Pendopo, Masjid, dan jaringan jalan raya pertama yang di bangun (Dwiyanto, 2003).

Proses penimbunan rawa pada saat itu menggunakan peralatan dan teknologi yang masih sangat sederhana bisa mengeringkan sebuah rawa besar merupakan satu pencapaian yang sangat baik dari Raden Bei Tjkaradimeja, bukan hanya itu setelah rawa kering dan dibangun banyak fasilitas kota Cilacap. Atas jasa-jasa beliau pemerintah Hindia Belanda memberi gelar kehormatan yaitu gelar Tumenggung berdasarkan Besluit no 3 tertanggal 30 Juni 1846 (Algemeen Overzicht Van de Staatkundige Gesteldheid van Nederlandsch-Indie Over 1839-1848, Hal 39-40 Arsip Banyumas.).

Setelah pembangunan berbagai fasilitas dan mulai berkembangnya Kota Cilacap, masyarakat Banyumas mengusulkan agar posisi Cilacap yang semula hanya Afdeling Cilacap ditingkatkan menjadi kabupaten terpisah dari Kabupaten Banyumas.

\section{2) Pembangunan Pendopo Kabupaten}

Pembangunan Pendopo Kabupaten menjadi hal penting sebagai tempat terselenggaranya roda pemerintahan, adapun pendopo biasanya dibangun dengan beberapa fasilitas pendukung lainya. Secara tipologi konsep tradisional alun-alun Jawa selalu terkait dengan keberadaan bangunan publik yang menganut konsep Catur Tunggal yaitu alun-alun, masjid, pendopo kabupaten dan kantor keresidenan mengikuti pola konsep Jawa di sumbu utara selatan di kedua ujung alunalun terdapat rumah bupati, di sebelah barat terdapat masjid (Yulia, 2018).

Pembangunan pendopo Kabupaten Cilacap secara umum mengikuti pola dan konsep tradisional Jawa dengan fungsi pendopo sebagai pusat administrasi dan kediaman bupati, turut juga dibangun masjid di sebelah barat pendopo dan alun alun di arah selatan dengan bangunan pendopo mengarah ke pantai selatan. Pendopo dibangun setelah Rawa Si Glongong dikeringkan, Kyai Singawedana yang merupakan orang kepercayaan Raden Tumenggung Tjakrawerdnana II diperintahkan untuk membangun pendopo sebagai tempat tinggal dan pusat administrasi pemerintahan, bersama dengan Demang Canduk yang sudah mulai menebang pohon kayu jati yang akan digunakan sebagai bahan bangunan pendopo (Soedarto, 1975).

Kayu Jati yang digunakan sebagai bahan bangunan diambil dari hutan Penyarang di daerah Sidareja, dalam proses pengangkutan kayu jati ini bukan hal yang mudah mengingat jarak antara 
Sidareja dan Kota Cilacap sendiri jauh ditambah lagi dengan kondisi dan medan saat itu yang masih berupa hutan dan pegunungan menjadi tantangan berat. Arsitek dalam pembangunan pendopo ini yaitu Kyai Noerdiman Demang Gumelem (Purbalingga), dalam membangun pendopo ini Kyai Noerdiman memadukan gaya arsitek Jawa dengan Eropa (Belanda). Gaya Jawa terlihat dengan ciri utamanya yaitu empat tiang penyangga utama yang disebut Soko Guru dengan bahan kayu Jati Bungkus dari hutan Penyarang.

Konstruksi bangunan pendopo secara umum tidak berubah dari saat pertama dibangun dan sebagian bahan utama pendopo masih asli termasuk tiang Soko Guru masih asli dan belum pernah diganti, hanya saja di beberapa sudut ada renovasi seperti lantai yang sudah menggunakan keramik dan pondasi yang sudah ditinggikan lalu atap yang diganti dengan genteng dan beberapa renovasi lainnya tapi secara keseluruhan bangunan ini masih asli dan bentuknya pun tidak banyak berubah masih sama seperti saat di bangun (Wawancara Wirendra Tjakrawedaja 1 Maret 2021).

\section{3) Pembangunan Masjid}

Masjid Cilacap dibangun tahun 1844, pembangunan masjid ini merupakan bentuk dari perhatian Raden Tumenggung Tjakrawerdana II dalam kebutuhan rohani umat muslim Cilacap. Masjid ini dibangun dengan konstruksi sederhana menggunakan bahan kayu dari pulau Nusakambangan yang dipakai sebagai kerangka utamanya. Lokasi masjid yang pertama dibangun masih tetap sama tetapi pada tahun 1928 bangunan masjid dipugar dan diperluas dengan dibangun masjid Agung Cilacap yang baru dan terletak di sebelah barat alun-alun (Dwiyanto, 2003).

Rangka bangunan masjid lama di pindahkan ke Kecamatan Kawunganten oleh seorang penghulu masjid. Keberadaan masjid ini sangat penting, bukan hanya sebagai sarana ibadah umat islam tetapi juga menjadi tempat berbagai aktivitas lainnya seperti sekolah agama, hakim yang mengurusi perkara agama, kantor komisi urusan agama dan lain-lain yang masih berhubungan dengan kepentingan umat muslim baik dulu maupun sekarang fungsi utama masjid masih tetap sama yaitu sarana beribadah.

Konsep pembangunan Masjid ini sama seperti konsep pembangunan lingkungan pusat kabupaten di Priangan Timur, dengan menempatkan masjid di sebelah Barat Alun-alun dan di sebelah Utara terdapat pasar. Ini merupakan salah satu konsep kota tradisionla yang diadopsi oleh dari beberapa Kesultanan di Jawa seperti Cirebon dan Mataram (Agus \& Ryan, 2014)

\section{4) Pembangunan Jalan dan Fasilitas lainnya}

Berkembangnya kota Cilacap terutama setelah dibukanya Pelabuhan Cilacap berdampak pula pada perubahan sosial ekonomi masyarakat sekitar. Kota sebagai pusat pelayanan umum, perdagangan, dan kedudukan penguasa yang ditopang oleh perkembangan ekonomi mempunyai dampak terhadap perkembangan infrastruktur seperti komunikasi, transportasi, pendidikan, dan lainlain hal ini menjadi perangsang meningkatnya urbanisasi dari daerah lain atau pedesaan ke kota (Kartodirdjo, 1990).

Pertumbuhan di Kota Cilacap ditandai dengan keragaman masyarakat yang hidup di Cilacap, keragaman itu antara lain adanya masyarakat Pribumi, Cina, dan Belanda yang masing-masing hidup dengan membentuk pola pemukiman sendiri. Pola pemukiman ini mencirikan pluralisme yang ada di Cilacap tetapi di lain sisi juga menunjukan tingkat stratifikasi sosial yang ada terutama pada masa kolonialisme warna kulit menjadi pembeda status sosial (Eko, 2001).

Penempatan lokasi permukiman ini berada di daerah pinggiran (pheriperi) kota yaitu di bagian barat dan selatan kota, dalam membangun tempat pemukiman ternyata Belanda sangat mempertimbangkan aspek lingkungan dan keindahan (Junawan, 1998). Hal ini terlihat dari penempatan lokasi yang berada di tepi barat dan selatan kota yang dekat dengan pelabuhan sehingga bisa melihat pemandangan pantai dan pulau Nusakambangan. Selain pemukiman, mereka 
juga mendirikan kantor kantor dan bangunan pendukung lainnya seperti Societet Verpozing, kantor pos, stasiun, sekolah, gereja, Hotel Belle Vie, kantor pelabuhan dan gudang pelabuhan.

Pemukiman masyarakat Cilacap secara umum tersusun rapi dan teratur, pasca tahun 1848 permukiman ini sudah memiliki jalan jalan dan tata ruang yang teratur dengan total ada 12 ruas jalan baik yang lurus maupun yang berpotongan. Untuk jalan utama sendiri yang melintasi pendopo Kabupaten ditanami berbagai pohon oleh Raden Tumenggung Tjakrawerdana II. Jalan utama dalam kota yang masing-masing lurus ke arah selatan menuju kantor residen, ke arah barat menuju pelabuhan Cilacap, ke arah timur menuju teluk penyu. Jalan utama yang mengarah ke selatan menjadi jalan yang sangat penting hal ini karena di sepanjang jalan ini terdapat banyak kantor-kantor pemerintahan kolonial dan semua aktifitas orang Belanda (Eko, 2001).

\section{5) Pembangunan Pelabuhan Cilacap}

Pelabuhan Cilacap mulai diperhatikan secara serius untuk kepentingan ekonomi terutama ekspor dan impor setelah wilayah Banyumas menjadi daerah kekuasaan Hindia Belanda, hal ini karena melihat potensi yang dimiliki pantai Cilacap untuk pelayaran serta memanfaatkan sungaisungainya yang bisa digunakan untuk mengangkut hasil perkebunan dari wilayah pedalaman Banyumas dengan pertimbangan bahwa pelabuhan di wilayah pantai utara Jawa sangat jauh dan membutuhkan biaya tempuh yang besar (Purnawan, 2019).

Pelabuhan Cilacap mulai terlihat aktivitas ekspor impornya saat praktek Tanam Paksa diterapkan tahun 1830 oleh Gubernur Jenderal Van den Bosch, secara umum praktek tanam paksa ini diambil dari sistem tanam kopi yang ada di Priangan (Preanger Stelsel) kemudian menyebar ke seluruh Jawa dan luar Jawa. Secara umum rakyat diwajibkan menyerahkan hasil perkebunan sebagai ganti pajak uang untuk tanah yang digarap para petani tanaman yang wajib di tanam pada saat itu yakni kopi, tebu, tembakau, dan teh untuk kopi sendiri pada saat itu menjadi komoditas utama dalam kegiatan ekspor impor di pelabuhan Cilacap. Dalam jangka waktu tiga tahun, setiap kepala rumah tangga di Keresidenan Banyumas harus menanam sebanyak 450 batang pohon dan terus bertambah seiring berjalannya kebijakan tanam paksa yang diterapkan (Zuhdi, 2019).

Perhatian awal Pemerintah Kolonial Hindia Belanda terhadap pelabuhan Cilacap mulai terlihat sejak tahun 1830. Pada tanggal 4 Desember 1830 pemerintah Hindia Belanda mengeluarkan keputusan pos Nusakambangan dimasukan kedalam garnisun kecil di pulau Jawa. Pembicaraan serius kembali mengemuka pada masa Gubernur Jenderal J.J. Rouchussen (1845-1851) seperti yang tertuang dalam keputusan tanggal 29 November 1847 mengatakan bahwa pembukaan pelabuhan hanya difokuskan untuk pelabuhan saja, tetapi saat darurat pelabuhan ini bisa digunakan sebagai jalur pelarian menuju Australia (Zuhdi, 2019).

Pembukaan pelabuhan Cilacap yang semula hanya pelabuhan kecil milik nelayan setempat, mulai dibangun dengan mengerahkan tenaga kerja kasar masyarakat lokal dan ini menjadi mega proyek pelabuhan yang ada di pantai Selatan Jawa adapun biaya pembangunanya ditanggung pemerintah Hindia Belanda sedangkan untuk tenaga kerja memberdayakan masyarakat lokal Cilacap dan ada sebagian dari daerah lain seperti Banyumas, Bagelen dan sekitarnya (Dwiyanto, 2003).

Dua belas tahun kemudian Pemerintah Hindia Belanda mulai menaruh perhatian terhadap pelabuhan Cilacap yang bukan hanya digunakan sebagai pelabuhan kecil untuk kegiatan ekspor impor pemerintah saja, tetapi juga bisa digunakan oleh pihak swasta. Keinginan tersebut diwujudkan dengan rencana pembukaan 16 pelabuhan di Jawa dan salah satunya yaitu pelabuhan Cilacap (Busandoro, 2019).

Pada masa Bupati Tjakraweradan II Pelabuhan Cilacap hanya melayani aktivitas perdagangan kecil, fasilitas transportasi yang belum memadai menjadi salah satu kendala dalam berkembangnya pelabuhan Cilacap, jalur darat hanya sedikit yang dapat digunakan meskipun sudah 
banyak jalan darat yang menghubungkan Banyumas dan sekitarnya akan tetapi jalan ini masih berupa jalan sederhana, sedangkan jalan yang menghubungkan Banyumas dan Cilacap belum bisa dilalui gerobak atau pedati. Jalan ini hanya bisa dilalui dengan jalan kaki dan selebihnya menggunakan jalur sungai yaitu Sungai Serayu yang menghubungkan wilayah bagian timur Cilacap dan Sungai Citanduy yang menghubungkan Cilacap bagian barat.

\section{6) Pembuatan Kali Yoso}

Jalur sungai memiliki peran penting dalam setiap kegiatan masyarakat begitupun dengan sungai Serayu, sungai ini menjadi salah satu sungai terbesar yang ada di Jawa. Sungai Serayu bermata air di Gunung Prau Dieng mengalir ke selatan melewati daerah Kejajar, Garung, dan Ledok (Wonosobo sekarang) dari ledok berbelok ke selatan sampai di Leksono airnya membelok ke barat melewati Sigaluh, Banjarnegara, Purwanegara, Mandiran, Purwareja Klampok, dan Kota Banyumas terus mengalir ke selatan hingga Cilacap dan bermuara di Samudera Hindia, dalam kurun waktu yang lama sungai ini menjadi bagian tak terpisahkan dari masyarakat Banyumas yang secara sosial ekonomi bermata pencaharian sebagai petani sehingga peran sungai ini menjadi sangat sentral digunakan sebagai media pengairan untuk sawah atau ladang-ladang masyarakat selain itu dengan arus Sungai Serayu yang tenang sehingga bisa dilayari kapal-kapal kecil, Sungai Serayu memiliki banyak anak sungai yang mengalir melewati banyak daerah, diantaranya yaitu Sungai Donan yang mengalir dari Distrik Jeruk Legi mengalir ke arah selatan dan bermuara di Segara Anakan. Sungai Citanduy yang mengalir disepanjang batas daerah Cirebon dan Priangan Timur sungai ini menjadi salah satu sungai terpanjang yang dapat dilalui oleh perahu sampai ke Pedalaman, Sungai Citanduy juga menjadi pembatas batas administratif Keresidenan Priangan Timur dan Keresidenan Banyumas (Busandoro, 2019).

Setelah dibangunnya Pelabuhan Cilacap membawa angin segar bagi perkebunan yang ada di Banyumas, pengangkutan hasil perkebunan dilakukan melalui beberapa jalur yaitu jalur darat dan jalur sungai, untuk jalur sungai sendiri Sungai Serayu menjadi yang paling sering digunakan karena arus yang tenang dan sungainya yang dalam. Setelah ditemukan solusi untuk mengangkut hasil perkebunan masalah selanjutnya yaitu muara Sungai Serayu berada jauh dari pelabuhan Donan dan ini menjadi kendala karena harus menyusuri pantai Cilacap yang ombaknya besar untuk masuk ke Pelabuhan Donan yang berada di Segara Anakan, sehingga muncullah sebuah ide untuk membuat sebuah terusan yang menghubungkan sungai Serayu dan pelabuhan Donan. Harapan para pejabat kolonial di Banyumas dengan adanya jalur transportasi pengangkutan hasil perkebunan ke negara induk melalui Sungai Serayu dan Pelabuhan Cilacap sebelum jalan darat yang tersedia bisa digunakan sungai menjadi fokus utamanya. Daya angkut dalam jumlah besar pada saat itu hanya bisa menggunakan perahu, jika menggunakan jalan darat hanya tenaga manusia yang bisa digunakan dengan jarak yang jauh sehingga membutuhkan biaya yang besar dan daya angkutnya pun sangat terbatas. Proyek-proyek di selatan Banyumas dianggap sangat penting oleh pemerintah Kolonial Hindia Belanda, terbukti dengan seriusnya pemerintah dalam membanguan berbagai infrastruktur di wilayah selatan Jawa terutama di Karesidenan Banyumas. Melalui Besluit nomor 3 tertanggal 12 September 1832 pemerintah kolonial di Batavia menganggarkan f 14.000 untuk membiayai proyek tersebut, direncanakan dengan selesainya proyek tersebut Gubernur Jenderal Van den Bosch akan berkunjung ke Cilacap (Busandoro, 2019).

Fasilitas yang dibangun oleh Raden Tumenggung Tjakrawerdana II semasa beliau memerintah di Cilacap sampai sekarang beberapa bangunan peninggalan beliau masih difungsikan dan terawat dengan baik, selain dari uraian di atas masih banyak sumbangsih yang beliau berikan untuk kemajuan kota baru di Pesisir Selatan Banyumas, sampai sekarang Cilacap terus tumbuh dengan semangat pembangunan demi terciptanya kesejahteraan bagi masyarakat Cilacap. 
Penelitian ini merupakan satu upaya dari pelestarian sejarah lokal dan merekonstruksi sejarah yang selama ini terlupakan dari masyarakat Cilacap terutama peran tokoh lokal, selama ini hanya tokoh-tokoh atau pahlawan nasional yang menjadi bahan pembelajaran dan tokoh daerah banyak yang tidak dikenal oleh masyarakat disekitarnya (Herdianti, Wijayanti, \& Sondarika, 2021).

\section{KESIMPULAN}

Raden Bei Tjakradimeja dilahirkan di Banyumas yang merupakan putra dari Bupati Cakrawerdana I Bupati Banyumas Kasepuhan. Di usia muda sudah diangkat menjadi Patih Banyumas dan kemudian tanggal 2 Oktober 1839 diangkat menjadi Patih Afdeling Cilacap karena prestasinya yang baik tanggal 27 Juni 1841 Raden Bei Tjakradimeja mendapat anugerah gelar "Tumenggung" dan status Afdeling Cilacap ditingkatkan menjadi Onder-Kabupaten dengan ibukotanya Cilacap. Peranan Bupati Cilacap pertama Raden Tumenggung Tjakrawerdana II dalam membangun Kota Cilacap terhitung dari tahun 1839 sampai dengan tahun 1873, adapun peranannya dalam membangun kota Cilacap yaitu mengeringkan Rawa Si Glongong, membangun pendopo kabupaten lengkap dengan masjid dan alun-alun sebagai pusat pemerintahan, membangun gedung Asisten-residen dan jalan sebagai fasilitas penunjang transportasi darat, pembangunan pelabuhan Cilacap, pembangunan kali Yoso, dan masih banyak fasilitas lain yang turut dibangun pada masa Bupati Raden Tumenggung Tjakrawerdana II.

\section{REKOMENDASI}

Penelitian ini direkomendasikan untuk bisa menjadi referensi bagi masyarakat Cilacap dalam pengembangan sejarah lokal dan bisa menjadi bahan kajian penelitian selanjutnya. Bagi Pemerintah Kabupaten Cilacap hasil penelitian ini bisa menjadi acuan dalam penyusunan Sejarah Cilacap dan bisa direkomendasikan menjadi mata pelajaran muatan lokal untuk diajarkan di sekolah-sekolah di seluruh Kabupaten Cilacap.

\section{UCAPAN TERIMAKASIH}

Penulis mengucapkan terimakasih kepada pihak-pihak yang sudah membatu dalam penelitian ini baik itu pembimbing dan narasumber yang bersedia diwawancarai oleh peneliti sehingga penelitian ini bisa diselesaikan tepat waktu dan dengan hasil yang baik.

\section{DAFTAR PUSTAKA}

Anri. Allgemeen Overzicht van de Staatkudige Geatelheid van NederlandschIndie Over 1830-1848.

Basundoro, P. (1999). Trasportasi dan Ekonomi di Keresidenan Banyumas Tahun 1830-940. Tesis. Universitas Gajah Mada.

Basundoro, P. (2019). Arkeologi Trasortasi Prespektif ekonomi dan Kewilayahan Karasidenan Banyumas 1830-1940. Surabaya. Airlangga University Press.

Budiman, A., \& Ardiansyah, R. (2014). Perpindahan Ibukota Kabupaten Sukapura dari Sukapura ke Manojaya serta dampaknya (1828-1834). Jurnal Artefak, 2 (1), 77-85.

Daliman, A. (2018). Metode Penelitian Sejarah. Penerbit Ombak. Yogyakarta.

Dwiyanto, B. (2003). Profil Pimpinan-Pimpinan Sejarah Kabupaten Cilacap. Cilacap; Dinas P dan K Kabupaten Cilacap. 
Herdianti, D., Wijayanti, Y., \& Sondarika, W. (2021). Pembelajaran Sejarah Contextual Teaching And Learning Situs Jambansari Dengan Metode Ekskursi Di SMA Informatika Ciamis. J-KIP (Jurnal Keguruan dan IImu Pendidikan), 2 (2), 55-62.

Gottschalk, L. (2008). Mengerti Sejarah. Penerbit UI Perss. Jakarta.

Kuntowijoyo. (2013). Pengantar IImu Sejarah. Yogyakarta. Penerbit Tiara Wacana.

Pratiwi, Y. (2018). Perbandingan Pola, Fungsi, dan Aksesibilitas Alun-alun Kabupaten Karanganyar, Kabupaten Sukoharjo, dan Kabupaten Klaten. Jurnal Arsitektur, Bangunan, dan Lingkungan UII Yogyakarta. 7 (2), 55-66.

Ratih, D. (2017). Kabupaten Ciancang dalam Perspektif Sejarah Lokal. Jurnal Artefak, 4 (1), 67-76.

Sjamsudin, H. (2020). Metodologi Sejarah. Yogyakarta. Penerbit Ombak.

Sondarika, W. (tt). Dampak Culturestelsel (Tanam Paksa) Bagi Masyarakat Indonesia dari Tahun 1830-1870. Hal 59-66.

Tjakrawedaja, W. 37 Tahun. Salah satu keturunan Raden Tumenggung Tjakrawerdana II. Tanggal 1 Maret 2021 Soedarmajdi. 83 Tahun. Manta dokter rumah sakit Banyumas. Tanggal 28 Maret 2021.

Triwarso, E.P. (2001). Kota Cilacap Tahun 1848-1942. Yogyakarta. Fakultas Sastra Universitas Gajah Mada.

Viliana, A.T. (2018). Peran Pelabuhan Cilacap Bagi Pertumbuhan Sosial Ekonomi Masyarakat Cilacap (1830-1942). Skripsi. Universitas Negeri Yogyakarta.

Zuhdi, S. (2016). Cilacap 1830-1942. Bangkit dan Runtuhnya Suatu Pelabuhan di Jawa. Yogyakarta. Penerbit Ombak. 